\title{
Opinion Mining Terhadap Toko Online Di Media Sosial Menggunakan Algoritma Naïve Bayes (Studi Kasus: Akun Facebook Dugal Delivry)
}

\author{
Yustia Hapsari ${ }^{1}$, Muhammad Fikri Hidayattullah ${ }^{2 *}$, Dairoh $^{3}$, Mohammad Khambali ${ }^{4}$ \\ ${ }^{1}$ Jurusan Teknik Informatika, STMIK YMI Tegal \\ 2,3 Jurusan Teknik Informatika, Politeknik Harapan Bersama Tegal \\ ${ }^{4}$ JurusanTeknik Listrik, Politeknik Negeri Semarang \\ ${ }^{1}$ Jl. Pendidikan, Pesurungan Kidul, Kota Tegal, Jawa Tengah 52147, Indonesia \\ ${ }^{2,3} \mathrm{Jln}$. Mataram No.09 Pesurungan Lor, Kota Tegal 52147, Indonesia \\ ${ }^{4} \mathrm{Jln}$. Prof. H. Soedarto, S.H., Tembalang, Semarang 50275, Indonesia \\ email: ${ }^{1}$ yustia.hapsari@gmail.com, ${ }^{2}$ fikri@ poltektegal.ac.id, ${ }^{3}$ dairoh@ poltektegal.ac.id, ${ }^{4}$ mc.chambali.poltek@gmail.com
}

Received: 30 Maret 2018; Revised:12 Mei 2018; Accepted: 13 Mei 2018

Copyright $\odot 2018$ Politeknik Harapan Bersama Tegal. All rights reserved

\begin{abstract}
The Internet era has had an impact in various sectors of human life. One is the economic sector. Economic transactions change from the traditional pattern (face to face) to online. The customer does not need to ask about the condition of an item to be purchased to a close friend or family, but simply by reviewing the product from the same buyer's comments. Products that get good reviews mean good quality. However, a problem arises if the comment data is very large and will make it difficult for customers to summarize the quality. Therefore, an automatic opinion mining system is required which can directly give conclusions about the quality of a product. This research makes an opinion mining system by applying the Naïve Bayes algorithm by taking a case study of facebook account Dugal Delivry. The measurement result with confusion matrix gives precision value of $88,89 \%$, recall $80 \%$ and accuracy equal to $85 \%$.
\end{abstract}

Abstrak - Era internet memberikan dampak di berbagai sektor kehidupan manusia. Salah satunya adalah sektor ekonomi. Transaksi ekonomi berubah dari pola tradisional (face to face) ke online. Customer tidak perlu bertanya tentang kondisi suatu barang yang akan dibeli ke teman dekat atau keluarganya, namun cukup dengan melihat review produk dari komentar para pembeli produk yang sama sebelumnya. Produk yang mendapat review bagus berarti berkualitas baik. Namun muncul sebuah masalah jika data komentar tersebut jumlahnya sangat besar dan akan menyulitkan customer dalam menimpulkan kualitasnya. Oleh karena itu dibutuhkan sebuah sistem opinion mining otomatis yang dapat secara langsung memberikan kesimpulan tentang kualitas suatu produk. Penelitian ini membuat sebuah sistem opinion mining dengan menerapkan algoritma Nä̈ve Bayes dengan mengambil studi kasus akun facebook Dugal Delivry. Hasil pengujian dengan

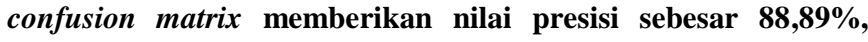
recall sebesar $80 \%$ dan akurasi sebesar $85 \%$.

Kata Kunci : opinion mining, sentiment analysis, Nä̈ve Bayes

*) Corresponding author: Muhammad Fikri Hidayattullah Email: fikri@poltektegal.ac.id

\section{PENDAHULUAN}

Perkembangan teknologi internet membawa dampak perubahan pada beberapa sektor kehidupan manusia, mulai dari pendidikan, perdagangan, pemerintahan hingga komunikasi sosial. Banyak pola baru dalam kehidupan manusia yang muncul setelah adanya perkembangan teknologi internet dan merubah pola lama (tradisional). Salah satu bentuk perubahan pola tersebut yang secara massif terjadi dimana-mana adalah dalam transaksi jual beli. Internet mengubah pola jual beli dari face to face menjadi transaksi online dengan segala tawaran kemudahannya. Ditambah lagi dengan munculnya media sosial seperti facebook, twitter, instagram dan whatsapp yang dapat dijadikan sebagai sarana untuk jual beli online tanpa perlu membuat toko online berbasis website.

Salah satu langkah yang biasa dilakukan oleh seorang customer sebelum memutuskan untuk membeli barang di toko online adalah melihat review dari para pembeli produk yang sama sebelumnya yang menuliskan opini dan tanggapan mereka tentang kondisi barang maupun pelayanan dari toko online tersebut. Langkah ini sangat membantu para customer sebelum memutuskan membeli sebuah produk tanpa bertanya terlebih dahulu kepada orang lain. Akan tetapi kendala akan muncul manakala jumlah opini dan tanggapan yang ada jumlahnya sangat banyak. Hal ini akan menyulitkan customer dalam menarik kesimpulan. Oleh karena itu diperlukan opinion mining otomatis yang dapat mengolah kata dan frase tentang ulasan suatu produk untuk membantu memberikan kemudahan dalam menyimpulkan kondisi barang dan pelayanan dari sebuah toko online [1]. Opinion mining merupakan nama lain dari sentiment analysis. Opinion mining merupakan sebuah bidang studi yang menganalisis pendapat, sentimen, emosi, sikap dan penilaian dari orangorang tentang suatu produk, layanan, individu, organisasi, topik, masalah, peristiwa beserta atributnya [2]. Melalui opinion mining dapat diketahui kecenderungan para customer 
terhadap suatu produk. Opinion mining bisa digunakan pada beberapa studi kasus, seperti review film [3], mengulas wacana politik pada media online [4][5], klasifikasi partai politik [6] hingga dapat digunakan untuk mengukur popularitas kandidat presiden [7][8]. Oleh karena riset di dalam opinion mining selalu berkembang terus.

Pada penelitian ini akan melakukan opinion mining terhadap komentar-komentar di facebook dengan mengambil sampel studi kasus akun facebook Dugal Delivry. Facebook merupakan salah satu media sosial yang lebih populer di dunia dibandingkan dengan mdeia sosial lainnya. Pada tahun 2012 saja facebook sudah memiliki 1 miliar pengguna aktif bulanan dan lebih dari 550 juta pengguna aktif harian [9]. Sedangkan untuk metode klasifikasi menggunakan algoritma Nä̈ve Bayes. Algoritma ini memiliki kelebihan yaitu mampu melakukan klasifikasi dengan baik dengan hanya membutuhkan sejumlah kecil data training [10]. Hasil dari penelitian ini akan menentukan nilai sentimen positif atau negatif dari kumpulan komentar yang diujikan.

\section{PENELITIAN YANG TERKAIT}

Penelitian terkait analisis sentimen atau penggalian opini telah dilakukan oleh beberapa peneliti, diantaranya dilakukan oleh Gusriani et al.[11] dengan melakukan analisis sentimen terhadap toko online di sosial media menggunakan metode klasifikasi Nä̈ve Bayes. Pada penelitian tersebut mengambil objek studi kasus facebook page (FP) BerryBenka. Tahapan penelitian yang dilakukan meliputi data collecting dengan melakukan crawling terhadap komentar-komentar dari para customer di FP BerryBenka, dilanjutkan proses preprocessing dengan melakukan punctuation and number filter dan case folding, setelah itu masuk ke tahap feature selection dan attribute selection, kemudian masuk ke tahap klasifikasi dengan algoritma nä̈ve bayes. Metode pengujian menggunakan $k$-Fold Cross Validation dan Confusion Matrix. Dari hasil pengujian diperoleh nilai akurasi $93.7 \%$.

Penelitian lain tentang analisis sentimen juga dilakukan oleh Liu et al[12]. Penelitian ini bertujuan untuk mengevaluasi skalabilitas algoritma Nä̈ve Bayes Classifier (NBC) ketika digunakan dalam data berskala besar. Sistem analisis Big Data juga dirancang untuk penelitian ini. Hasilnya menggembirakan karena akurasi NBC meningkat dan mendekati $82 \%$ ketika ukuran dataset juga meningkat.

Pada tahun 2016 Dey et al.[10] melakukan penelitian seputar sentimen analisis untuk mendapatkan hasil review film dan hotel secara cepat. Pada penelitian ini juga mengkomparasi keakuratan, presisi, serta nilai recall dua algoritma klasifikasi untuk kasus sentimen analisis yaitu KNN dan Nä̈ve Bayes. Dan algoritma Nä̈ve Bayes memberikan hasil akurasi jauh lebih baik daripada K-NN untuk kasus review film yaitu sebesar $82,43 \%$, sedangkan untuk akurasi K-NN-nya sebesar 69,81\%. Untuk kasus review hotel memberikan hasil akurasi kurang lebih sama, $55,09 \%$ untuk Nä̈ve Bayes dan 52,14\% untuk K-NN.

Penelitian yang khusus berfokus menganalisis performa algoritma Nä̈ve Bayes untuk klasifikasi data telah dilakukan oleh Patil dan Sherekar[13]. Pada penelitian ini melakukan studi komparasi antara algoritma Nä̈ve Bayes dengan J48 classification yang berbasis algoritma decision tree. Pada penelitian ini memberikan hasil akurasi klasifikasi untuk algoritma Nä̈ve Bayes dengan klasifikasi YES sebesar 9\% dan NO sebesar 89\%. Sedangkan untuk algoritma J48 menghasilkan akurasi YES sebesar $31 \%$ dan NO sebesar $87 \%$.

\section{ALGORITMA NAÏVE BAYES}

Algoritma Nä̈ve Bayes didasarkan dari aturan Bayes. Meskipun algoritma ini dari sisi penamaan kurang meyakinkan karena menggunakan istilah "naive", namun memiliki performa yang bagus ketika diuji cobakan pada dataset yang aktual [14]. Di dalam kasus opinion mining algoritma ini digunakan untuk mengklasifikasikan hasil sentimen.

$$
P(\mathrm{Ci} \mid \mathrm{X})=\frac{P(X \mid C i) P(C i)}{P(X)}
$$

$\mathrm{P}(\mathrm{Ci} \mid \mathrm{X})$ : probabilitas posterior

$\mathrm{P}(\mathrm{X} \mid \mathrm{Ci})$ : probabilitas prior

$\mathrm{P}(\mathrm{X} \mid \mathrm{Ci})$ : likelihood

$\mathrm{P}(\mathrm{X})$ : evidence

Atau dapat juga dituliskan [15]:

$$
\text { Posterior }=\frac{\text { Likelihood } * \text { Prior Probability }}{\text { Evidence }}
$$

\section{METODE PENELITIAN}

\section{A. Alur Perancangan}

Di dalam penelitian ini tahapan awal dari pengumpulan data hingga pengujian akurasi opinion mining dapat dilihat di Gbr 1.

\section{a) Data Collecting}

Tahap awal dari penelitian ini adalah pengumpulan data (data collecting). Pada tahap ini melakukan pengambilan data-data komentar dari akun facebook Dugal Delivry. Setelah data terkumpul akan dilanjutkan dengan proses seleksi data training (training data selection).

\section{b) Preprocessing}

Tahapan preprocessing merupakan tahapan persiapan awal sebelum masuk ke proses berikutnya [15]. Di dalam tahap ini ada tiga proses yang dilakukan. Pertama adalah Tokenization. Tahap ini berguna untuk memecah data-data komentar dalam bentuk kalimat yang akan diproses. Di dalam tahap ini juga terjadi penghapusan tanda baca dan angka. Tahap kedua adalah Stop Word Removal. Tahap ini berfungsi menghilangkan kata-kata yang sering muncul dan tidak begitu memiliki makna dalam proses opinion mining, seperti kata "dan", "yang", "atau" dan lain sebagainya. Sedangkan tahap ketiga yaitu stemming, berfungsi menjadikan kata yang telah mendapatkan sisipan kembali ke kata dasarnya, misalkan "membelikan" akan berubah menjadi "beli".

\section{c) Classification}

Classification merupakan tahap terakhir dalam opinion mining. Tahap ini berfungsi untuk menentukan nilai sentimen terhadap suatu produk atau layanan. Algoritma yang 
digunakan dalam tahap ini adalah Nä̈ve Bayes. Di dalam penelitian ini hanya ada dua nilai hasil sentimen yaitu positif dan negatif.

\section{d) Measurement Accuration}

Tahap terakhir ini bertujuan untuk menguji tingkat akurasi opinion mining dengan algoritma Naïve Bayes. Metode perhitungan akurasi yang dilakukan dengan menggunakan confusion matrix.

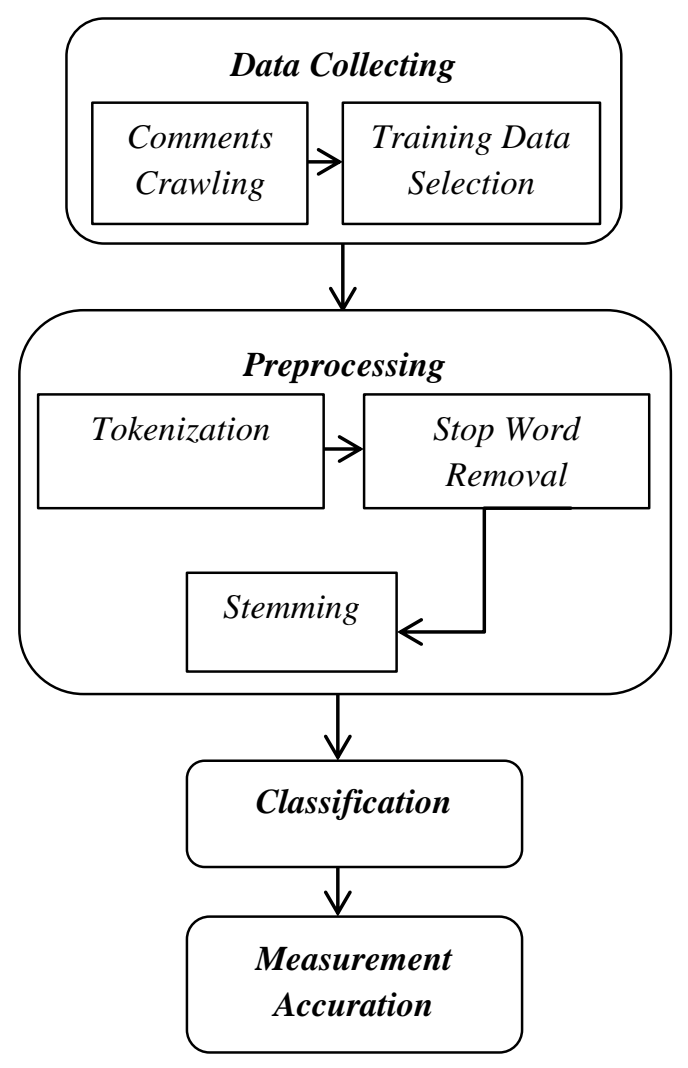

Gbr. 1 Tahapan Opinion Mining

\section{HASIL DAN PEMBAHASAN}

Data training yang digunakan dalam penelitian ini berjumlah sebanyak 49 komentar bernilai positif dan 26 komentar bernilai negatif. Kumpulan komentar negatif dan positif yang dijadikan sebagai data training dibutuhkan untuk penentuan hasil pengujian data testing. Komentar-komentar tersebut diambil dari data komentar di akun facebook Dugal Delivry. Sedangkan untuk data testing berjumlah 10 data bernilai positif dan 10 data bernilai negatif. Data testing digunakan untuk menghitung nilai akurasi. Tools yang digunakan untuk penentuan nilai opini adalah Rapid Miner.

Setelah seluruh data training terkumpul semua akan dilanjutkan tahap preprocessing dengan melakukan proses penghilangan tanda baca dan angka yang tertulis di komentar-komentar para customer. Tujuan dari preprocessing ini adalah untuk membersihkan data training dari noise, mengurangi volume jumlah kata dan menyeragamkannya. Tanpa melalui proses preprocessing akan ditemukan banyak data yang mengandung kata-kata yang kurang berarti dan memiliki makna.

Tahap selanjutnya adalah feature selection. Tahap ini berisi filtering dan stemming. Stemming merupakan suatu proses mengubah sebuah kata yang telah mendapatkan sisipan menjadi kata dasar. Hanya saja kamus standar stemming Bahasa Indonesia di Rapid Miner belum tersedia, sehingga harus memanfaatkan kamus eksternal. Tahapan feature selection inni sangat diperlukan sebelum masuk ke proses pelatihan data di Nä̈ve Bayes.

Tahap terakhir sebelum masuk pengujian akurasi dalam opinion mining adalah tahap klasifikasi. Algoritma klasifikasi yang digunakan adalah Nä̈ve Bayes. Tahap ini akan menghasilkan klasifikasi opini positif atau negatif.

TABEL I

Hasil Pengujian Data Testing

\begin{tabular}{|c|c|c|}
\hline No. & Kalimat yang dianalisis & $\begin{array}{l}\text { Nilai opini } \\
\text { (sentimen) }\end{array}$ \\
\hline 1. & $\begin{array}{l}\text { ah mimin banyak diemnya kalo } \\
\text { dikomen.. }\end{array}$ & Negatif \\
\hline 2. & Kambing lo... & Negatif \\
\hline 3. & Lama bgt datangnya & Negatif \\
\hline 4. & Min, klapertartnya keenceran nih & Negatif \\
\hline 5. & bisa lbh cepet ga dtgnya... & Negatif \\
\hline 6. & Dikomen ga balas-balas & Negatif \\
\hline 7. & Payah nih mimin.. & Negatif \\
\hline 8. & rasanya tidak enak & Positif \\
\hline 9. & $\begin{array}{l}\text { Jangan mahal-mahal dong.. kasih } \\
\text { diskon banyakin }\end{array}$ & Negatif \\
\hline 10. & Lama nunggunya om admin & Negatif \\
\hline 11. & Lezat banget kuenya & Positif \\
\hline 12. & $\begin{array}{l}\text { Mantab deh pokoknya..duriannya } \\
\text { kerasa banget }\end{array}$ & Positif \\
\hline 13. & Enak.. & Positif \\
\hline 14. & bikin anakku ketagihan min.. yummy & Positif \\
\hline 15 . & $\begin{array}{l}\text { wah, pengen nambah lagi } \\
\text { pesenannya.. enak sih soalnya }\end{array}$ & Positif \\
\hline 16. & Yummi.. & Negatif \\
\hline 17. & $\begin{array}{l}\text { Alhamdulillah, pesenanku dah sampai } \\
\text { min.. mantab deh pokoknya }\end{array}$ & Positif \\
\hline 18. & rasanya mantab dan lezat...jos & Negatif \\
\hline 19. & Rasanya emang enak bgt & Positif \\
\hline 20. & Alhamdulillah dah nyampe mbak.. & Positif \\
\hline
\end{tabular}

Kesalahan hasil klasifikasi pada data testing negatif terdapat pada kalimat "rasanya tidak enak". Kesalahan klasifikasi ini disebabkan tidak mampunya sistem opinion mining ini menegasikan kata "tidak" (convert negation). Sehingga setiap kali ada kata "tidak" disambungkan dengan kata bermuatan opini positif akan dianggap sebagai opini positif. Padahal kalimat tersebut merupakan opini negatif dan bentuk negasi dari opini positif.

Pengujian akurasi menggunakan confusion matrix yang meliputi perhitungan presisi, recall dan akurasi. Proses perhitungan ini berdasarkan perolehan jumlah True Positive 
(TP), True Negative (TN), False Positive (FP) dan False Negative (FN).

TABEL II

KLASIFIKASI CONFUSION MATRIX

\begin{tabular}{|l|l|l|}
\hline \multicolumn{1}{|c|}{ Kelas } & \multicolumn{1}{|c|}{$\begin{array}{c}\text { Terklasifikasi } \\
\text { Positif }\end{array}$} & \multicolumn{1}{|c|}{$\begin{array}{c}\text { Terklasifikasi } \\
\text { Negatif }\end{array}$} \\
\hline Positif & $\begin{array}{l}\text { True Positive } \\
(\mathrm{TP})\end{array}$ & $\begin{array}{l}\text { False Negative } \\
(\mathrm{FN})\end{array}$ \\
\hline Negatif & $\begin{array}{l}\text { False Positive } \\
(\mathrm{FP})\end{array}$ & $\begin{array}{l}\text { True Negative } \\
(\mathrm{TN})\end{array}$ \\
\hline
\end{tabular}

Dari hasil pengujian diperoleh nilai:

$$
\begin{aligned}
& \text { Presisi }=\frac{\mathrm{TP}}{\mathrm{FP}+\mathrm{TP}} * 100 \% \\
& \text { Presisi }=\frac{8}{1+8} * 100 \%=88,89 \% \quad \text { Recall }=\frac{8}{2+8} * 100 \%=80 \% \\
& \text { Akurasi }=\frac{\mathrm{TP}+\mathrm{TN}}{\mathrm{TP}+\mathrm{TN}+\mathrm{FP}+\mathrm{FN}} * 100 \% \\
& \text { Akurasi }=\frac{8+9}{8+9+1+2} * 100 \%=85 \%
\end{aligned}
$$

Melalui pengujian confusion matrix diperoleh hasil untuk presisi sebesar $88,89 \%$, recall sebesar $80 \%$ dan akurasi sebesar $85 \%$.

\section{KESIMPULAN}

Algoritma Nä̈ve Bayes terbukti cukup handal diterapkan dalam kasus klasifikasi opinion mining. Algoritma ini mampu menghasilkan nilai presisi sebesar $88,89 \%$, recall sebesar $80 \%$ dan akurasi sebesar $85 \%$. Namun, jika diamati salah satu penyebab kesalahan klasfikasi adalah tidak adanya fitur convert negation. Fitur convert negation sangat diperlukan sekali karena untuk menghindari kesalahpahaman classifier ketika mengklasifikasikan frase atau kalimat yang mengandung kata "tidak". Oleh karena itu untuk pengembangan ke depan perlu ditambah fitur convert negation dan perlu adanya optimasi algoritma Nä̈ve Bayes.

\section{DAFTAR PUSTAKA}

[1] R. Othman, R. Belkaroui, and R. Faiz, "Extracting Extracting Product Product Features Features for for Opinion Opinion Mining Mining
Using Public Conversations in Twitter Using Public Conversations in Twitter," Procedia Computer Science, vol. 112, pp. 927-935, 2017.

[2] B. Liu, "Sentiment Analysis and Opinion Mining," Synthesis Lectures on Human Language Technologies, no. May, 2012.

[3] L. L. Dhande and P. G. K. Patnaik, "Analyzing Sentiment of Movie Review Data using Naive Bayes Neural Classifier," International Journal of Emerging Trends \& Technology in Computer Science (IJETTCS), vol. 3, no. 4, pp. 313-320, 2014.

[4] M. Ringsquandl and D. Petković, "Analyzing Political Sentiment on Twitter," Analyzing Microtext: Papers from the 2013 AAAI Spring Symposium, pp. 40-47, 2013.

[5] A. Bakliwal, J. Foster, J. Van Der Puil, R. O. Brien, L. Tounsi, and M. Hughes, "Sentiment Analysis of Political Tweets: Towards an Accurate Classifier," Proceedings of the Workshop on Language in Social Media (LASM 2013), no. Lasm, pp. 49-58, 2013.

[6] T. Ding, J. Deng, J. Li, and Y. Lin, "Sentiment Analysis and Political Party Classification in 2016 U . S . President Debates in Twitter," International Conference on Social Computing, Behavioral-Cultural Modeling, \& Prediction and Behavior Representation in Modeling and Simulation, pp. 1-6, 2016.

[7] R. Malinský and I. Jelínek, "Sentiment Analysis: Popularity of Candidates for the President of the United States," International Journal of Humanities and Social Sciences, vol. 6, no. 12, pp. 3679 3681, 2012.

[8] E. Tunggawan, "And the Winner is ...: Bayesian Twitter-based Prediction on 2016 U . S . Presidential Election," IC3INA 2016 Conference (3-5, no. 1, pp. 1-5, 2016

[9] A. Ortigosa, J. M. Martín, and R. M. Carro, "Computers in Human Behavior Sentiment analysis in Facebook and its application to elearning," COMPUTERS IN HUMAN BEHAVIOR, 2013.

[10] L. Dey, S. Chakraborty, A. Biswas, B. Bose, and S. Tiwari, "Sentiment Analysis of Review Datasets using Naïve Bayes' and KNN Classifier," Information Retrieval (cs.IR); Computation and Language (cs.CL), vol. 8, no. 4, pp. 54-62, 2016.

[11] S. Gusriani, K. D. K. Wardani, and M. I. Zul, "Analisis Sentimen Terhadap Toko Online di Sosial Media Menggunakan Metode Klasifikasi Naïve Bayes ( Studi Kasus ... Analisis Sentimen Terhadap Toko Online di Sosial Media," 4th Applied Business and Engineering Conference, no. November, 2016.

[12] B. Liu, E. Blasch, Y. Chen, D. Shen, E. Blasch, Y. Chen, D. Shen, and G. Chen, "Scalable sentiment classification for Big Data analysis using Naïve Bayes Classifier Scalable Sentiment Classification for Big Data Analysis Using $\mathrm{Na}$ “ 1ve Bayes Classifier," IEEE Intl Conf. on Big Data, no. October 2013, 2014.

[13] T. R. Patil and S. S. Sherekar, "Performance Analysis of Naive Bayes and J48 Classification Algorithm for Data Classification," International Journal Of Computer Science And Applications, vol. 6, no. 2, 2013.

[14] I. H. Witten, E. Frank, and M. A. Hall, Data Mining: Third Edition. Elsevier Inc., 2011.

[15] F. Gorunescu, Data Mining: Concepts,Models and Techniques, 12th ed. Springer, 2011 